\title{
Shear Strengthening of Concrete Members with Unbonded Transverse
} Reinforcement

\author{
Mathieu Fiset ${ }^{\mathrm{a}}$, Josée Bastien ${ }^{\mathrm{b}}$, Denis Mitchell ${ }^{\mathrm{c}}$ \\ a Département de génie civil et de génie des eaux, Université Laval, 1065, av. de la Médecine, Québec \\ (Québec), G1V 0A6, Canada, mathieu.fiset.1@ulaval.ca (Corresponding author) \\ ${ }^{\mathrm{b}}$ Département de génie civil et de génie des eaux, Université Laval, 1065, av. de la Médecine, Québec \\ (Québec), G1V 0A6, Canada, josee.bastien@gci.ulaval.ca \\ ${ }^{c}$ Department of Civil Engineering and Applied Mechanics, McGill University, 817 Sherbrooke Street \\ West, Montreal (Quebec) H3A 0C3, Canada, denis.mitchell@mcgill.ca
}

Declarations of interest: none

\section{ABSTRACT}

This paper examines the behaviour of thick concrete members strengthened in shear with unbonded transverse reinforcement. The retrofitting technique consists of placing unbonded vertical bars with steel end plates or torque controlled expansion end anchorages in pre-drilled holes of existing thick members. To study the behaviour of these members, loading tests as well as numerical analyses were carried out. Shear capacities were compared to the predictions using the shear design approach in the Canadian Highway Bridge Design Code. The design equations which are intended for traditional stirrups reinforcement overestimates the shear capacities of the members strengthened with unbonded transverse reinforcement. However, numerical analyses provided very accurate predictions of the shear capacities. A finite element parametric study examines the effects of the shear span-to-depth ratio, vertical prestressing, shear reinforcement ratio and the stiffness of the vertical reinforcement. The stiffness of the shear strengthening system and the effects of prestressing significantly affect the shear capacity. The shear capacities were predicted well when a minimum amount of vertical prestressing was provided.

Key words: Reinforced Concrete, Shear Strengthening, Shear Behaviour, Shear Strength, Unbonded bars, Finite Element Modelling 
27 Numerous concrete bridges have been subjected to concrete degradation, steel corrosion as well as 28 increased loading and frequency of traffic. This may result in insufficient flexural and shear capacities. 29 The one-way shear failure of the "La Concorde" overpass in Laval (Canada) in 2006 showed that many 30 thick concrete slab bridges without shear reinforcement may require shear strengthening [1,2]. This event 31 is one of many examples illustrating the fact that shear failure of concrete members without shear reinforcement is very brittle. The critical diagonal crack propagates rapidly accompanied by a sudden drop in shear capacity, often without any warning of the impending failure. To prevent such a brittle 34 failure mode, concrete thick slabs should contain a minimum amount of shear reinforcement [1]. Members with an appropriate minimum amount of shear reinforcement are capable of redistributing the stresses and controlling shear cracking.

Adhikary and Mutsuyoshi [3] have tested several shear strengthening techniques in beams. They found that the most effective method to increase the member shear capacity consisted of clamping transverse reinforcing bars on the existing concrete member and to anchor the bars extremities using mechanical anchorages. Unlike conventional transverse reinforcement (stirrups installed before concrete casting), the added bars are typically unbonded to the concrete. Although this clamped shear strengthening technique has been commonly used by engineers, only a limited number of studies are devoted to shear failure investigations for members with shear span-to-depth ratio $(a / d)$ over 2.5. Many authors have studied 44 flexural failures of shear strengthened beams with vertical unbonded bars, but very few studied the influence on the shear failure behaviour. The effects of unbonded transverse reinforcement on the shear strength of slender beams were studied experimentally by Suntharavadivel [4], Elstner and Hognestad [5] and Lechner and Feix [6], while Ferreira, Bairán et al. [7] performed finite element analyses. These authors have observed that before shear cracking, unbonded transverse reinforcement shows almost no 
49 increase in strain. However, at the shear cracking load, strains in the unbonded bars increased until beam

50 failure occurred. After diagonal cracking, the shear is transferred to the shear reinforcement until the 51 critical diagonal crack becomes so large that shear failure occurs. This behaviour was also observed for 52 deep beams and slabs $[3,4,8-10]$.

53 By keeping the total transverse reinforcement ratio $\left(\rho_{v}\right)$ constant and progressively replacing stirrups by 54 unbonded bars, Altin, Tankut et al. [11] showed that the same failure mode and similar load capacities 55 can be achieved. However, they observed that replacing embedded stirrups by unbonded bars reduces the 56 member deformation capacity. Shear strengthened beams with only unbonded reinforcement also showed 57 only a small number of diagonal cracks compared to beams with internal stirrups. Elstner and Hognestad 58 [5], Khaloo [12], Shamsai, Sezen et al. [13] have also shown that prestressing the unbonded vertical bars 59 enables a further increase of the shear capacity so that the failure mode may shift from a brittle shear to a 60 ductile flexural failure.

\section{1.1. $\quad$ Research significance}

62 This paper focuses on the behaviour of thick concrete members, representing thick slabs, that has been 63 strengthened using unbonded drilled-in transverse reinforcement. This retrofitting consisted of inserting 64 bars in pre-drilled holes into an existing member and anchoring the bars with steel end plates or torque65 controlled expansion anchorages. These two techniques can be used for the shear retrofit of thick concrete 66 slabs, particularly those without any stirrups. A complementary finite element (FE) investigation was 67 performed to better understand the shear behaviour of such members. In addition, a parametric study was 68 carried out to examine the effects of the shear span-to-depth ratio, vertical prestressing, the shear 69 reinforcement ratio and the stiffness of the shear strengthening system on the shear behaviour. 


\section{EXPERIMENTAL PROGRAM}

\section{2.1. Strengthening Techniques}

72 Experimental tests were carried out on beams representing slices of thick concrete slabs. The retrofitting consisted of drilling vertical holes into the existing concrete structure and inserting a reinforcing bar in each hole. For practical considerations, drilling of holes and bars installation are typically performed from the top of the member. Two shear strengthening systems illustrated in Fig. 1 were used. Fig. 1a presents mechanically anchored treaded bars (hole diameter $d_{h}=24.0 \mathrm{~mm}$, bar diameter $d_{b}=15.9 \mathrm{~mm}$ with a net

bar area $A_{b}=146 \mathrm{~mm}^{2}$ ) used to strengthen beam specimens type T in Fig. 2. The lower bar extremity is anchored with torque controlled expansion anchorages and an anchor plate is installed to anchor the top extremity at the beam top surface. When torqued, the expansion of the bottom anchor exerts lateral pressure on the internal surface of the hole, which produces frictional forces to provide anchorage. Another shear strengthening system (Fig. 1b) was used for specimens type P (see Fig. 2) which consists of inserting high-strength \#9 reinforcing bars $\left(d_{h}=40.0 \mathrm{~mm}, d_{b}=28.7 \mathrm{~mm}, A_{b}=645 \mathrm{~mm}^{2}\right)$ with threaded ends into drilled holes and anchored with nuts and plates at the top and bottom of the concrete beam surfaces. The main advantage of these two strengthening techniques is that they can be used in wide beams or structural thick slabs to resist shear. The strengthening technique used in type T members can be used in a positive moment region to avoid cutting longitudinal tension reinforcement located in the bottom of a member during the installation procedure. Otherwise, the strengthening technique used in type P members can be used in a negative moment region or when drilling can easily be performed avoiding cutting through the longitudinal tension reinforcement.

For comparison purposes, two additional sets of beams were tested (Fig. 2). Specimens type S contained conventional stirrups $\left(d_{b}=15.9 \mathrm{~mm}\right.$ and $\left.A_{b}=200 \mathrm{~mm}^{2}\right)$ installed before the concrete was cast while 
92 specimens type $\mathrm{U}$ represent control specimens that did not contain any shear reinforcement and was not 93 retrofitted.

\section{2.2. Details of Test Specimens}

95 The specimen dimensions, material properties and strengthening details are summarized in Table 1 and 96 Fig. 2. All of the test specimens span $4 \mathrm{~m}$, have a total height, $h$, of $750 \mathrm{~mm}$ and a width, $b_{w}$, of $610 \mathrm{~mm}$.

97 A normal-strength concrete with a maximum aggregate size, $a_{g}$, of $20 \mathrm{~mm}$ was used. The concrete compressive strength, $f_{c}^{\prime}$ and Young's modulus, $E_{c}$, were measured on cylinders according to ASTMC39, ASTM-C469, respectively and the average properties are summarized in Table 1.

100 Specimen type U contains one layer of longitudinal reinforcing bars (nominal bar diameter, $d_{b}$, of 25.2 $101 \mathrm{~mm}$ ) located at a effective depth, $d$, of $699 \mathrm{~mm}$, having a total area, $A_{s}$, of $5000 \mathrm{~mm}^{2}$ and a yield strength, $f_{y}$, of $468 \mathrm{MPa}$. Specimen types $\mathrm{S}, \mathrm{T}$ and $\mathrm{P}$ contain a total area of longitudinal reinforcement $A_{s}=7000 \mathrm{~mm}^{2}$ at $d=694 \mathrm{~mm}$ and having $f_{y}=508 \mathrm{MPa}$ and $d_{b}=29.9 \mathrm{~mm}$.

104 While specimen type $\mathrm{U}$ did not contain any shear reinforcement, specimen types $\mathrm{S}, \mathrm{T}$ and $\mathrm{P}$ were 105 designed to have more than the minimum amount of shear reinforcement $\rho_{v, \text { min }}$ required by CSA-S6 [14] 106 (see Eq. (1)). The stirrups used in the specimens type $\mathrm{S}$ have a total area $A_{v}$ of $400 \mathrm{~mm}^{2}$ and were 107 installed at a spacing $s$ of $380 \mathrm{~mm}$ (shear reinforcement ratio $\rho_{v}=A_{v} /\left(b_{w} s\right)=0.17 \%$ ). Specimens type $108 \mathrm{~T}$ was shear strengthened with vertical bars having $A_{v}=292 \mathrm{~mm}^{2}, s=380 \mathrm{~mm}, \rho_{v}=0.13 \%$ and 109 anchored with torqued controlled expansion anchorage. The tensile capacity $F_{u}$ of the torque controlled 110 anchorages is $90.8 \mathrm{kN}$ according to the compressive strength of the concrete mix used [15]. Specimens 
111 type $\mathrm{P}$ have one set of bars in the middle of the shear span so that the total area $A_{v}$ is $1290 \mathrm{~mm}^{2}$. Young

112 modulus, $E_{s}=200000 \mathrm{MPa}$, hardening strain, $\varepsilon_{s h}=2.3 \%$ and strain at failure, $\varepsilon_{u}=18 \%$ were measured

113 on stirrups and were consider similar for all steel used. The other mechanical properties of shear

114 reinforcing bars are summarized in Table 1, where $f_{u}$ is the tensile strength.

$$
\rho_{v, \min }=0.06 \frac{\sqrt{f_{c}^{\prime}}}{f_{y}} \quad \text { (MPa units) }
$$

116 2.3. Test Setup and Instrumentation

117 The test setup is shown in Fig. 2. The loading was applied in several load steps at a constant midspan

118 deflection rate of $0.17 \mathrm{~mm} / \mathrm{min}$. The shear span, $a$, was $2000 \mathrm{~mm}$ so that the shear span-to-depth ratio

$119 a / d$ was about 2.9. At each load stage, the midspan deflection was kept constant while measurements

120 were taken. After the occurrence of a shear failure in one half of the beam, the specimen was unloaded

121 and steel shear clamping devices were added to the failed half span in order to reload the beam until

122 failure of the other half span. The midspan deflection was monitored using a linear variable differential

123 transformer (LVDT) and the applied load was measured using a load cell. Strain gauges were installed to

124 measure the transverse reinforcing bar strains (Fig. 2). LVDTs in a form of rosettes were installed on the 125 side faces of the beams at the middle of the shear spans.

\section{$126 \quad 2.4 . \quad$ Experimental Results}

127 Table 2 and Fig. 3 to Fig. 5 summarize the experimental results. In Fig. 3 showing the cracking of the 128 specimens at failure, the diagonal crack leading to the shear failure is represented with a bold line while 129 the other experimental cracks are identified with thinner lines. As observed by Altin, Tankut et al. [11], 130 specimens with stirrups (S1 and S2) in Fig. 3 exhibited a larger number of diagonal cracks than the 
131 specimens with unbonded bars (types $\mathrm{T}$ and $\mathrm{P}$ ). For comparison, the specimens without shear

132 reinforcement (type $\mathrm{U}$ ) and shear strengthened specimens type $\mathrm{T}$ exhibited only one large critical shear

133 crack while specimens P1 and P2 experienced two diagonal cracks; the larger one leading to failure. For

134 the specimens with stirrups, S1 and S2, the strain in the shear reinforcement increased when the first

135 diagonal crack at cracking shears, $V_{c r}$, of $495 \mathrm{kN}$ and $484 \mathrm{kN}$, respectively. Specimens $\mathrm{S} 1$ and S2, with

136 stirrups, failed at a shear of $726 \mathrm{kN}$ and $809 \mathrm{kN}$, respectively. Fig. 6 shows some selected strain

137 measurements for specimen S2 indicating that yielding of the stirrups occurred (refer to Fig. 2 for

138 transverse reinforcement numbering and strain gauge locations). Fig. 6 also compares the difference in

139 strains measured in the top and bottom portions of the stirrups.

140 For specimens without shear reinforcement (type U), shear failure occurred shortly after the sudden

141 propagation of a large diagonal crack. This sudden crack propagation was also observed for the

142 specimens with unbonded shear reinforcement but did not lead to immediate failure. The shear cracking

143 propagation is responsible for the observed peaks of the shear versus deflection curve, at about $490 \mathrm{kN}$, as

144 shown in Fig. 4. Each of these intermediate peaks was followed by the sudden propagation of a large

145 diagonal crack and reductions in shear of about $85 \mathrm{kN}$ and $60 \mathrm{kN}$ on average for specimens $\mathrm{T}$ and $\mathrm{P}$,

146 respectively. The sudden propagation of a large diagonal crack and the associated decrease in load was

147 not observed for beams with stirrups (S1 and S2). The influence of shear failure on one side followed by

148 unloading, shear strengthening and reloading is apparent from the load versus deflection responses shown

149 in Fig. 6.

150 Before shear cracking, the unbonded shear reinforcing bars in specimens type P experienced low strains

151 (Fig. 6) and opening of a diagonal crack is required to activate the unbonded bars. For specimens P1 and

$152 \mathrm{P} 2$, the strains increased from 150 to 632 microstrains $\left(f_{s}=30\right.$ to $\left.127 \mathrm{MPa}\right)$ and from 175 to 471 
153 microstrains $\left(f_{s}=35\right.$ to $\left.94 \mathrm{MPa}\right)$ after the crack propagation respectively. After their activation, the

154 transverse bars carry some additional shear.

155 After initial shear cracking, no new diagonal cracks propagated in specimens T1 and T2 up to the shear

156 failure while two diagonal cracks formed at shears of $696 \mathrm{kN}$ and $671 \mathrm{kN}$ in specimens $\mathrm{P} 1$ and P2,

157 respectively. Failure of specimen P1 occurred shortly after initiation of the second diagonal crack ( $V_{\text {exp }}=$

$158717 \mathrm{kN}$ ) and at a higher shear of $969 \mathrm{kN}$ for P2. The failure of both specimens P1 and P2 occurred after

159 crushing of the concrete and significant slip, $\delta$, of the critical diagonal crack. At failure, the average

160 strains of the transverse bars were 1585 and 2215 microstrains $\left(f_{s}=317\right.$ and $\left.443 \mathrm{MPa}\right)$ for $\mathrm{P} 1$ and $\mathrm{P} 2$,

161 respectively. These measured strains indicated stresses below the yield stress of the reinforcing bars $\left(f_{y}=\right.$

$162517 \mathrm{MPa})$.

163 The additional shear capacity offered by shear strengthening can be determined by comparing the

164 maximum experimental capacity, $V_{\text {exp }}$, to the capacity at diagonal cracking, $V_{c r}$. In average, the addition

165 of unbonded shear reinforcement led to a shear capacity increase of about $20 \%$ and $72 \%\left(V_{\text {exp }} / V_{c r}\right)$ for

166 specimens $\mathrm{T}$ and $\mathrm{P}$, respectively. This ratio is an indicator of the efficiency of the shear strengthening

167 techniques.

\section{MODIFIED COMPRESSION FIELD THEORY}

169 The modified compression field theory (MCFT) [16-18] enables the determination of the shear behaviour

170 of elements with and without shear reinforcement. According to the MCFT, the shear nominal capacity,

$171 V_{n}$, is the summation of the shear carried by the concrete $V_{c}$ and by the transverse reinforcement $V_{s}$

172 according to Eq. (3) and (4), where $f_{c 1}$ is the tensile stress in cracked concrete (Eq.(5)) limited by the 
173 aggregate interlock capacity $v_{c i}$ in Eq. (6), $d_{v}$ the effective shear depth taken as $0.9 d, f_{s}$ is the bar stress 174 and $d_{v} \cot \theta / s$ being the amount of shear reinforcement crossing the diagonal cracks.

$$
\begin{gathered}
V_{n}=V_{c}+V_{s} \\
V_{c}=f_{c 1} \cot \theta b_{w} d_{v} \leq v_{c i} b_{w} d_{v} \\
V_{s}=\frac{A_{v} f_{s} d_{v} \cot \theta}{s} \\
f_{c 1}=\frac{f_{c r}}{1+\sqrt{c \varepsilon_{c 1}}} \\
v_{c i}=\frac{0.18 \sqrt{f_{c}^{\prime}}}{0.31+24 w /\left(16+a_{g}\right)} \text { (MPa, mm units) }
\end{gathered}
$$

180 The simplification of these equations led to the shear design method used in the codes in Eq. (7) to (11) 181 [14]. The nominal concrete shear capacity is determined from the factor $\beta$ in Eq. (9) (SI units), which 182 results from the simplification of Eq. (5) with $c=500$ and Eq. (6). It considers the average horizontal 183 strain $\varepsilon_{x}$ in Eq. (10), for the case of moment and shear only, and the equivalent crack spacing $S_{z e}$, which 184 is taken as $300 \mathrm{~mm}$ for members respecting $\rho_{v, \text { min }}$ defined by Eq. (1), or as $35 d_{v} /\left(15+a_{g}\right)$ otherwise. 185 The nominal transverse reinforcement shear capacity considers no slip between concrete and shear 186 reinforcement $\left(\varepsilon_{c}=\varepsilon_{s}\right)$ and their yielding at shear failure $\left(f_{s}=f_{y}\right)$. The angle of the compression field $187 \theta$ with respect to the longitudinal member axis is determined by Eq. (11) for members with shear 188 reinforcement.

$$
V_{c}=\beta \sqrt{f_{c}^{\prime}} b_{w} d_{v} \quad(\mathrm{MPa}, \mathrm{mm} \text { units })
$$




$$
V_{s}=\frac{A_{v} f_{y} d_{v} \cot (\theta)}{s}
$$

$$
\beta=\left(\frac{0.4}{1+1500 \varepsilon_{x}}\right)\left(\frac{1300}{1000+s_{z e}}\right) \text { (mm units) }
$$

$$
\varepsilon_{x}=\frac{M / d_{v}+V}{2 E_{s} A_{s}}
$$

$$
\theta=29+7000 \varepsilon_{x}
$$

\section{FINITE ELEMENTS MODELLING}

\section{4.1. Mesh Description}

196 The finite element (FE) program VecTor2 [19] was used to study the behaviour of the specimens and the 197 parameters influencing their behaviour. The modelling approach is based on the MCFT [18] and 198 Disturbed Stress Field Model (DSFM) [20]. Because of the geometry involved and loading symmetry, 199 half of each beam was modelled (see Fig. 7 for typical mesh layout).

200 Fig. 8 illustrates the chosen approach to model the bars and anchorages. Two-dimensional discrete truss 201 elements were used to simulate the transverse reinforcing bars and the longitudinal reinforcement. For 202 conventional stirrups perfect bond was assumed between the bar and the concrete (see Fig. 8a) so that $203 u_{s}=u_{c}$. For the truss element representing unbonded bars, only the far extremities of the truss element are 204 linked to the anchor elements nodes (Fig. 8b and c). To simulate the anchor plate (specimen types $\mathrm{T}$ and 205 P), truss elements extremities are linked to bearing elements installed on the top of beams. The stiffness 206 of these bearing elements is determined according to the stiffness of the anchor system. To simulate the 207 torqued-controlled anchor behaviour (specimen type T), contact elements are used to allow slippage 208 between the concrete and the steel bars at the bottom anchorage locations (Fig. 8c). 


\subsection{Material Behaviour}

210 The adopted concrete and steel stress-strain behaviour are illustrated in Fig. 9. As shown in Fig. 9a, the

211 tensile behaviour of plain concrete is linear up to the cracking strain, $\varepsilon_{c r}$, and the cracking strength $f_{c r}$

212 (assumed as $0.33 \sqrt{f_{c}^{\prime}}$ ). It respects the tension softening proposed by Yamamoto and Vecchio [21] after

213 cracking. The post cracking tensile behaviour of reinforced concrete considers tension stiffening

214 according to Eq. (5), where $c$ is the tension stiffening coefficient determined according to the

215 reinforcement ratio [20, 22-24]. At a crack, the aggregate interlock limits the concrete tensile stress and

216 the resulting crack slip, $\delta$, is determined according the approach proposed by Vecchio and Lai [25]. The

217 dowel effect is implicitly considered in the FE model by reducing the shear demand at crack, which

218 reduces the crack slip and increases the shear capacity [19].

219 In compression, the modified Popovics relationship $[19,26,27]$ illustrated in Fig. $9 \mathrm{~b}$ ( $f_{c 2}$ is the concrete 220 compressive stress and $\varepsilon_{p}$ is the compressive strain at peak stress $f_{p}$ ) was chosen and the behaviour 221 takes into account the concrete confinement effect and the compression softening effect $[28,29]$. The 222 steel behaviour in Fig. 9c is bilinear up to the strain hardening strain, $\varepsilon_{s h}$, (Eq. (12)). The hardening 223 stress-strain relationship is given by Eq. (13), where $P$ is the strain-hardening parameter taken as 1 for 224 steel plate elements and 4 for truss bar elements.

$$
\begin{gathered}
f_{s}=E_{s} \varepsilon_{s} \leq f_{y} \quad \varepsilon_{s} \leq \varepsilon_{s h} \\
f_{s}=f_{u}+\left(f_{y}-f_{u}\right)\left(\frac{\varepsilon_{u}-\varepsilon_{s}}{\varepsilon_{u}-\varepsilon_{s h}}\right)^{P} \quad \varepsilon_{s h}<\varepsilon_{s} \leq \varepsilon_{u}
\end{gathered}
$$

227 The force-slip relationship shown in Fig. 9d is used to simulate the anchor axial behaviour in specimens type T was fitted to experimental tests performed by Collins, Klingner et al. [30] and Hilti [31]. The 
229 initial anchor stiffness is taken as $14 \mathrm{kN} / \mathrm{mm}$ up to $0.35 F_{u}$. The anchor maximum capacity is reached at a

230 displacement $s_{u}$ of $7.5 \mathrm{~mm}$ on average. It decreases up to $3 s_{u}$ with a residual capacity of $0.9 F_{u}$.

\section{5. COMPARISONS OF PREDICTIONS WIDTH RESULTS}

\section{5.1. The Canadian Highway Bridge Design Code (CHBDC)}

233 It can be seen in Table 2 that the shear capacities of the specimens with stirrups and without shear

234 reinforcement are predicted well $\left(V_{n} / V_{\text {exp }}=1.07\right)$ by the code provisions while, as expected, it greatly

235 overestimates $\left(V_{n} / V_{\text {exp }}=1.27\right)$ the capacity of the specimens with unbonded shear reinforcement. This 236 overestimation of shear strength is explained by the fact that the bars are unbonded and hence are not as 237 effective in controlling diagonal cracks. The code CSA-S6 [14] considers that $s_{z e}=300 \mathrm{~mm}$ for members 238 with $\rho_{v} \geq \rho_{v, \text { min }}$. Even if this minimum ratio is respected for specimen types $\mathrm{T}$ and $\mathrm{P}$, they experienced a 239 smaller number of diagonal cracks and a larger crack spacing in comparison to specimens S1 and S2. 240 Crack width, $w$, and crack spacing is influenced by the bond between concrete and reinforcing bars [32$24135]$. Therefore, unbonded shear reinforcing bars are not as effective in controlling the crack spacing.

242 While the standard design method is applicable for elements with conventional bonded stirrups it is not 243 applicable for elements with unbonded shear reinforcement. Finite element models are more appropriate 244 to predict the behaviour of a member with unbonded shear reinforcement.

\section{$245 \quad$ 5.2. Finite Element Predictions}

246 The finite element (FE) analysis provided very good predictions of the overall behaviour, including the 247 shear capacity. Fig. 3 to Fig. 6 compare the predicted responses from the FE analyses with the observed 248 behaviour of the specimens. The ratio of the predicted shear capacities using the finite element analysis 
and the experimental shear capacities $\left(V_{\text {exp }} / V_{F E}\right)$ is 1.03 on average (COV of 0.10) (see Table 2). For 250 specimen S1, with stirrups, the finite element model predicted many diagonal cracks, as shown in Fig. 3,

251 while one critical diagonal crack was predicted for the other specimens. For specimens type P, the finite 252 element predictions agree well with the initiation of two diagonal cracks, the first one leading to failure. 253 Generally, the critical diagonal crack location was predicted to be closer to the midspan loading but both 254 the predicted and experimental critical shear cracks intercept the same number of transverse bars. The 255 predicted strains in the transverse reinforcement (Fig. 6) agree well with the experimental measurements 256 and resulted in good predictions of the behaviour of the specimens. The first shear cracking load is 257 underestimated by $123 \mathrm{kN}$ on average but the overall member behaviour is well predicted. The predicted 258 crack slip $\delta$ is smaller than the experimental measurements but the predicted crack widths agree well 259 with the experimental measurements. The predicted strains in Fig. 6 indicate that failure of specimens 260 type $\mathrm{T}$ and $\mathrm{P}$ occurred without yielding of the transverse reinforcement.

\section{5.3. Shear Resistance Mechanisms}

262 To analyze the shear resistance mechanisms in specimens $\mathrm{P} 1$ and $\mathrm{P} 2, V_{\text {exp }}$ versus $w$ is plot in Fig. 10. The 263 shear carried by $V_{s}$ is determined by the stress in reinforcing bars intercepting the main diagonal crack 264 and derived from Eq.(4) (see Fig. 10). The shear carried by the concrete, $V_{c}$, is limited by the aggregate 265 interlock and determined using Eq. (3). The shear carried by the dowel action is determined with Eq. (14) $266[36,37]$, where $\delta_{s}$ is the vertical crack displacement and $\ell_{d a}$ is the length of the splitting crack along the 267 longitudinal reinforcement.

$$
V_{d}=\frac{1.94 d_{b}^{2} A_{s} E_{s}}{\ell_{d a}^{3}} \delta_{s} \leq 1.62 A_{s} \sqrt{f_{c}^{\prime} f_{y}} \quad(\mathrm{MPa}, \mathrm{mm} \text { units })
$$


269 The length of the splitting cracks $\ell_{d a}$ determined from the experimental cracking pattern in Fig. 3 is 270 about $700 \mathrm{~mm}$ and $760 \mathrm{~mm}$ for the members $\mathrm{P} 1$ and P2, respectively. By comparing the shear resistance 271 mechanisms in Fig. 10, it can be seen that the shear carried by the dowel action is much lower than other 272 mechanisms. At shear failure, the shear carried by the dowel action is $29.6 \mathrm{kN}$ for the member P1 and $27332.5 \mathrm{kN}$ for the member P2, which represents $4.2 \%$ and $3.3 \%$ of the total shear, respectively. Also, it is 274 found that the summation of the aggregate interlock, the shear reinforcement resistance and the dowel 275 action $\left(V_{c}+V_{s}+V_{d}\right)$ resulted in lower predictions than the failure shear, $V_{\text {exp }}$. The contribution of a direct 276 compression strut between the loading location and the support $\left(V_{\text {strut }}\right)$ may also develop and hence play a 277 role in resisting shear [37-46]. This phenomenon is generally more significant for deep members with a 278 ratio $a / d$ lower than 2.5 [38-40] and few models developed in the last decades take into account this 279 mechanism [41-45]. The tested specimens had a shear span to depth ratio of 2.9 and exhibited a few shear 280 cracks, which enabled the development of the direct strut after significant shear cracking. As shown in 281 Fig. 10, at failure of specimens $\mathrm{P} 1$ and $\mathrm{P} 2, V_{\text {strut }}$ is about $172 \mathrm{kN}$ and $344 \mathrm{kN}$, respectively, which 282 represent $24 \%$ and $36 \%$ of the total shear. For comparison, the aggregate interlock limits $V_{c}$ to $138 \mathrm{kN}$ and $100 \mathrm{kN}(19 \%$ and $10 \%)$ and the value of $V_{s}$ is $377 \mathrm{kN}$ and $494 \mathrm{kN}(53 \%$ and $51 \%)$, respectively for 284 these specimens. Therefore, the concrete strut formation in the uncracked concrete depth contributes to 285 the total shear capacities of both P1 and P2 specimens. Specimens P1 and P2 failed due to concrete 286 crushing in compression, which is associated with the loss of $V_{\text {strut }}$. At a crack width of $3.6 \mathrm{~mm}$ at the

287 failure shear of specimen $\mathrm{P} 1$, both type $\mathrm{P}$ specimens exhibited similar values of $V_{c}, V_{s}$ and $V_{\text {strut }}$. At 288 failure specimen P2 had a larger strut component than P1 (see Fig. 10). This is confirmed by the FE 289 results presented in Fig. 11 showing the predicted principal concrete compressive stress, $f_{c 2}$, and shear 290 stress, $v_{c x y}$, at failure. The orientation of the concrete compressive stress is illustrated by lines in Fig. 11a, 
291 which confirm the presence of a compressive stress field between the loading location and the support.

292 Numerical integration of the shear stress in the uncracked concrete depth illustrated in Fig. 11b can be

293 used to estimate $V_{\text {strut }}$. Based on the FE analysis of type $\mathrm{P}$ members, one can determine that $V_{\text {strut }}=306$

$294 \mathrm{kN}$, which represents $39 \%$ of the predicted shear capacity $V_{f e}$.

\section{6. PARAMETRIC ANALYSIS}

296 A total of 127 finite element analyses were performed to analyze the effects of the shear span-to-depth 297 ratio, vertical pre-stressing, transverse bar spacing and vertical bar stiffness on the shear behaviour of the 298 strengthened member. The properties of the additional concrete members analyzed in this section are 299 presented in Fig. 12 and Table 3. In Table 3, the shear at flexural failure, $V_{f l e x}$, was determined according 300 to CSA-S6 [14]. The shear capacity of members without shear reinforcement, $V_{c}$ was determined from 301 finite element analysis and this value is used in the following section to evaluate the shear strengthening 302 efficiency.

303 Each additional shear strengthening cases studied utilized unbonded transverse reinforcing bars similar to 304 the ones used for members P1 and P2. To experience a possible size effect in shear, member heights 305 varied between $750 \mathrm{~mm}$ and $3000 \mathrm{~mm}$. A mesh similar to the ones used for the experimental tests is used 306 for these members (Fig. 7). Transverse reinforcement ratios, $\rho_{v}$, varies between 0 (no shear 307 reinforcement) to $\rho_{v, \max }$ (see Table 3), and different end anchorage stiffness values of the shear 308 strengthening were analyzed.

309 6.1. Shear span to depth ratio

310 Fig. 13 presents the effect of the shear span-to-depth ratio, $a / d$, on the ratio between the shear capacity 
311 provided by the direct strut action, $V_{\text {strut }}$, and the shear capacity, $V_{f e}$, both determined by FE analysis. For

312 comparison purposes, two shear reinforcement ratios, $\rho_{v}$, are presented as well as the FE capacities

313 determined for the type $\mathrm{P}$ and $\mathrm{T}$ tested members.

314 It can be seen that a large part of shear is carried by $V_{\text {strut }}$ for $a / d \leq 2.9$ as previously observed for the

315 experiments. However, the contribution of $V_{\text {strut }}$ is less $\left(V_{\text {strut }} / V_{n}<20 \%\right)$ as the shear span-to-depth ratio,

$316 a / d$, increases. This decreasing of $V_{\text {strut }}$ is similar to the one observed by increasing the shear-to-depth

317 ratio of members without shear reinforcement [37, 38].

318 For members with $a / d>2.9$, a large number of diagonal cracks were present, yielding of transverse

319 reinforcement crossing the critical diagonal crack was observed and transverse reinforcement between the

320 support and this diagonal crack were highly stressed (up to $f_{y}$ ). For comparison with members $a / d \leq 2.9$

321 and experimental tests, a large diagonal crack was present, transverse reinforcement crossing the main

322 shear crack did not reach their yielding strength and reinforcement between the support and the crack

323 experienced almost no stress. By increasing the $a / d$ ratio above 2.9 , the contribution of $V_{\text {strut }}$

324 significantly decreases while $V_{s}$ increases.

325 By comparing same members with different reinforcement ratio, it can be observed that by increasing the 326 shear reinforcement ratio $\rho_{v}$ the proportion of shear carry by $V_{\text {strut }}$ reduces. Generally, members with the 327 same amount of longitudinal reinforcement, shear span-to-depth ratio and material properties exhibit a 328 similar uncracked concrete depth [41-43], which results in a comparable value of $V_{\text {strut }}$. For example, $329 V_{\text {strut }}$ equals $284 \mathrm{kN}$ and $272 \mathrm{kN}$ for the two members P750a illustrated in Fig. $13\left(a / d=2.9, \rho_{v}=\right.$ 
$330 \quad 0.13 \%$ and $0.21 \%$ respectively). However, a larger amount of transverse reinforcement results in an

331 increased member shear capacity and therefore, in a smaller ratio $V_{\text {strut }} / V_{f e}$ as illustrated in Fig. 13.

\section{$332 \quad$ 6.2. $\quad$ Vertical Stiffness}

333 The transverse reinforcement stiffness is defined by the additional equivalent length, $\ell_{a}$, required to

334 represent the total shear reinforcement elongation $u_{t o t}$, which includes the anchorage displacement,

335 according to the bar elongation $u_{s}$ in Eq. (15). In these finite element analyses, $\ell_{a}$ varies between $0 \mathrm{~mm}$

336 (no anchor displacement) and $3500 \mathrm{~mm}$ (large part of the vertical displacement is due to the anchorage).

337 It is expected that this range covers a very large range of anchor flexibly. For comparison, specimen P1

338 experienced $u_{s}=1.2$ and $u_{t o t}=4.2 \mathrm{~mm}$, which results in an equivalent length $\ell_{a}$ of $1900 \mathrm{~mm}$.

$$
\ell_{a}=\left(\frac{u_{t o t}}{u_{s}}-1\right) \ell_{b a r}
$$

340 Fig. 14 and Fig. 15 present the shear versus deflection response of member P750b and the maximum

341 shear capacity of members P750a and P750b (see Table 3) for different amounts of transverse

342 reinforcement and shear strengthening system stiffness. While the predictions using CSA-S6 [14] are not

343 applicable for unbonded transverse reinforcement these predictions are shown in Fig. 14 to illustrate the

344 influence of the anchorage flexibility. For the three $\rho_{v}$ values given in Fig. 14, it can be observed that the

345 initial stiffness of the curves does not significantly differ for the range of the strengthening system

346 stiffness studied. For members with $\ell_{a}=0$ and $\rho_{v}$ of $0.13 \%$ and $0.17 \%$, a decrease of the shear versus

347 deflection stiffness is initiated at a shear cracking load of about $460 \mathrm{kN}$. Members with more flexible

348 shear strengthening systems $\left(\ell_{a}>0\right)$ experienced an abrupt load decrease which becomes more

349 significant as the amount of transverse reinforcement and the strengthening system stiffness decreases. 
350 However, this sudden load decrease is not observed for members with the highest amount of transverse

351 reinforcement $\left(\rho_{v}=0.52 \%\right)$ and $\ell_{a} \leq 1000 \mathrm{~mm}$. These members experienced higher shear cracking

352 loads ranging from $495 \mathrm{kN}$ to $615 \mathrm{kN}$ and their overall stiffness of the load-deflection curves decreases at 353 higher load levels.

354 It is interesting to observe in Fig. 14 that the decreased stiffness of the strengthening system, with $\ell_{a} \geq$

$3551000 \mathrm{~mm}$, shifts the failure mode of members from ductile bending failures to brittle shear failures with

356 smaller deflections at failure. Generally, the shear capacity decreases as the shear strengthening system

357 stiffness decreases due to a lower shear carried by the unbonded bars. Similar observations were reported 358 by Suntharavadivel [4], Elstner and Hognestad [5].

359 Fig. 15 illustrates the influence of different shear reinforcement ratios and strengthening stiffness values.

360 For the cases with $\rho_{v}=0.07 \%$ the transverse reinforcement ratio is less than $\rho_{v, \text { min }}$. Members with a very

361 flexible shear strengthening system may experience brittle shear failure instead of a ductile flexural

362 failure. It is clear that a member with very low amount of very flexible shear reinforcement may 363 experience brittle shear failure after shear cracking, consequently no increase of shear strength. This is the 364 case for member P750a with a reinforcing ratio of $\rho_{v}=0.07 \%$ and a very flexible shear strengthening $\left(\ell_{a}\right.$ $365=14000 \mathrm{~mm}$ not illustrated in Fig. 15).

\section{6.3. Vertical Prestressing}

367 Member P750a was analysed with different amounts of transverse prestressing in the unbounded bars 368 with $f_{p v}$ up to $390 \mathrm{MPa}$ (which includes prestress losses). The effect of vertical prestressing $\rho_{v} f_{p v}$ (force 369 par unit of concrete area) on shear capacity is illustrated in Fig. 16. It can be seen that vertical 
370 prestressing may significantly increases the shear capacity. Since the shear carried by the unbonded bars

371 is a function of the vertical crack displacement, increasing the amount of vertical prestressing reduces the

372 crack width and increases the aggregate interlock. Also, the increase in shear capacity is more significant

373 for members with flexible shear reinforcement $\left(\ell_{a}=2700\right)$ than members with stiff shear reinforcement (

$\left.374 \ell_{a}=75 \mathrm{~mm}\right)$. For flexible shear strengthening systems, the bar stress at failure is lower than $f_{y}$ while the

375 addition of prestressing may increase the bar stress up to $f_{y}$ and $V_{s}$ consequently increases. For example,

376 the stress in the transverse reinforcement at shear failure increased from $266 \mathrm{MPa}$ to $400 \mathrm{MPa}$ (equals to

$\left.377 f_{y}\right)$ with the addition of vertical prestressing of $195 \mathrm{MPa}\left(\rho_{v} f_{p v}=0.341 \mathrm{MPa}\right)$. The same amount of

378 prestressing has no significant effect on the shear capacity for member with $\ell_{a}=75 \mathrm{~mm}$ since the

379 transverse reinforcement was predicted to reach $f_{y}$ without prestressing.

\section{CONCLUSIONS}

381 This paper examines the shear behaviour of shear critical members with unbonded shear reinforcement 382 placed in holes drilled into the concrete. Eight experimental tests were performed and numerical analyses 383 were carried out. Shear capacities were compared to the predictions using the Canadian Highway Bridge 384 Design Code [14] for shear design and to predictions made with non-linear finite element analyses. The 385 finite element analyses resulted in very accurate predictions of the shear capacities, member responses 386 and cracking patterns. A parametric analysis was carried out to better understand the effect of the shear 387 span-to-depth ratio, amount of unbonded shear reinforcement, the stiffness of the anchorage of the shear 388 strengthening system and the use of vertical prestressing. The following conclusions are made based on 389 this study:

390 - Unbonded shear reinforcement increases the shear capacity and deformability; 
- Propagation of a sudden large diagonal crack caused a drop of the shear for members with unbonded shear reinforcement. This behaviour is very similar to the one observed for members without shear reinforcement at failure.

- After diagonal cracking, a large diagonal crack is required to activate the unbonded shear reinforcement and the concrete shear capacity is limited by aggregate interlock.

- The shear strengthening stiffness significantly affects the shear capacity. Stiff shear reinforcement experienced yielding at shear failure while more flexible unbonded shear reinforcement did not reach yield.

- Vertical prestressing increases the shear strengthening efficiency by increasing the shear capacities. With a sufficient amount of prestressing, members with a flexible shear strengthening system can experience a similar behaviour to members with stiff shear strengthening system;

- The Canadian Highway Bridge Design Code developed from the modified compression field theory implicitly assumes perfect bonded transverse reinforcement and hence is not applicable for prediction the shear capacity of unbonded shear reinforcement.

\section{ACKNOWLEDGEMENTS}

406 The research reported in this paper was made possible by funding from the Natural Sciences and 407 Engineering Research Council of Canada (NSERC, CREATE-INFRA) and the "Fonds de Recherche du 408 Québec - Nature et Technologies" (FRQNT). The authors also acknowledge the contributions of Benoit 409 Cusson and Philippe Provencher who performed the testing in the structures laboratory at Université 410 Laval. 


\section{REFERENCES}

412 [1] Mitchell D, Marchand J, Croteau P, Cook WD. Concorde Overpass Collapse: Structural Aspects. 413 Journal of Performance of Constructed Facilities. 2011;25:545-53. 414 https://doi.org/10.1061/(ASCE)CF.1943-5509.0000183

415 [2] Johnson PM, Couture A, Nicolet R. Commission of Inquiry Into the Collapse of a Portion of the De 416 La Concorde Overpass. Quebec, Canada: Gouvernement du Quebec; 2007. p. 198.

417 [3] Adhikary BB, Mutsuyoshi H. Shear Strengthening of Reinforced Concrete Beams Using Various 418 Techniques. Construction and Building Materials. 2006;20:366-73. 419 https://doi.org/10.1016/j.conbuildmat.2005.01.024

420 [4] Suntharavadivel TG. Retrofitting of Shear Damaged Reinforced Concrete Beams. In: Fragomeni S, 421 Venkatesan S, editors. Incorporating Sustainable Practice in Mechanics and Structures of Materials. 422 London UK: Taylor and Francis Group; 2010. p. 197-202.

423 [5] Elstner RC, Hognestad E. Laboratory Investigation of Rigid Frame Failure. ACI Journals. 424 1957;28:637-68.

425 [6] Lechner J, Feix J. Development of an efficient shear strengthening

426 method for dynamically loaded structures. In: Koichi Maekawa AK, Jun Yamazaki, editor. Proceedings 427 of The 11th fib International PhD Symposium in Civil Engineering. Tokyo, Japan2016. p. 753-61.

428 [7] Ferreira D, Bairán JM, Marí A. Shear Strengthening of Reinforced Concrete Beams by Means of 429 Vertical Prestressed Reinforcement. Structure and Infrastructure Engineering. 2016;12:394-410. 430 https://doi.org/10.1080/15732479.2015.1019893

431 [8] Teng S, Kong F-K, Poh SP, Guan LW, Tan K-H. Performance of Strengthened Concrete Deep Beams 432 Predamaged in Shear. ACI Structural Journal. 1996;93:159-71.

433 [9] El-Shafiey T, Atta A. Retrofitting of Reinforced Concrete Beams in Shear Using External Prestressing 434 Technique. Magazine of Concrete Research. 2012;64:201-2011. https://doi.org/10.1680/macr.10.00157

435 [10] Inácio MMG, Pinho Ramos A, Faria DMV. Strengthening of Flat Slabs with Transverse 436 Reinforcement by Introduction of Steel Bolts Using Different Anchorage Approaches. Engineering 437 Structures. 2012;44:63-77. http://dx.doi.org/10.1016/j.engstruct.2012.05.043

438 [11] Altin S, Tankut T, Anil Ö, Demirel Y. Response of Reinforced Concrete Beams with Clamps 439 Applied Externally: An Experimental Study. Engineering Structures. 2003;25:1217-29. 440 https://doi.org/10.1016/S0141-0296(03)00082-8

441 [12] Khaloo AR. Shear Repair of Reinforced Concrete Beams Using Post-Tensioning. ACI Special 442 Publication. 2000;193:519-49. 
443 [13] Shamsai M, Sezen H, Khaloo A. Behavior of Reinforced Concrete Beams Post-Tensioned in the 444 Critical Shear Region. Engineering 2007;29:1465-74. 445 https://doi.org/10.1016/j.engstruct.2006.07.026

446 [14] CSA-S6. Canadian Highway Bridge Design Code and Commentary. 11th ed. Mississauga, ON, 447 Canada: Canadian Standards Association; 2014.

448 [15] Hilti. Hilti Fastening Technology Manual B 2.11. Schaan, Liechtenstein2005. p. 384.

449 [16] Collins MP, Mitchell D, Adebar P, Vecchio FJ. A General Shear Design Method. ACI Structural 450 Journal. 1996;93:36-60.

451 [17] Bentz EC, Collins MP. Development of the 2004 CSA A23.3 Shear Provisions for Reinforced 452 Concrete. Canadian Journal of Civil Engineering. 2006;33:521-34. https://doi.org/10.1139/106-005

453 [18] Vecchio FJ, Collins MP. The Modified Compression-Field Theory for Reinforced-Concrete 454 Elements Subjected to Shear. ACI Journal. 1986;83:219-31.

455 [19] Wong PS, Vecchio FJ, Trommels H. Vector2-User's Manual. 2nd ed. Toronto, Canada: University of 456 Toronto; 2013.

457 [20] Vecchio FJ. Disturbed Stress Field Model for Reinforced Concrete: Formulation. Journal of 458 Structural Engineering. 2000;126:1070-7. https://doi.org/10.1061/(ASCE)0733-9445(2000)126:9(1070)

459 [21] Yamamoto T, Vecchio F. Analysis of Reinforced Concrete Shells for Transverse Shear and Torsion. 460 ACI Structural Journal. 2001;98:191-200.

461 [22] Bentz EC. Sectional Analysis of Reinforced Concrete Members. University of Toronto: University 462 of Toronto; 2000.

463 [23] Bentz EC. Explaining the Riddle of Tension Stiffening Models for Shear Panel Experiments. Journal 464 of Structural Engineering. 2005;131:1422-5. https://doi.org/10.1061/(ASCE)0733465 9445(2005)131:9(1422)

466 [24] Sato Y, Vecchio FJ. Tension Stiffening and Crack Formation in Reinforced Concrete Members with 467 Fiber-Reinforced Polymer Sheets. Journal of Structural Engineering. 2003;129:717-24. 468 https://doi.org/10.1061/(ASCE)0733-9445(2003)129:6(717)

469 [25] Vecchio FJ, Lai D. Crack Shear-Slip in Reinforced Concrete Elements. Journal of Advanced 470 Concrete Technology. 2004;2:289-300. https://doi.org/10.3151/jact.2.289

471 [26] Thorenfeldt E, Tomaszewicz A, Jensen JJ. Mechanical Properties of High-Strength Concrete and 472 Application in Design. In: Ivar Holand NB, editor. Proceedings of the Symposium Utilization of High 473 Strength Concrete. Stavanger, Norway: Tapir; 1987. p. 149-59.

474 [27] Collins MP, Mitchell D. Prestressed Concrete Structures. Englewood Cliffs, New Jersey, USA: 475 Prenticc-Hall; 1991. 
476 [28] Ottosen NS. Constitutive Model for Short-Time Loading of Concrete. Journal of the Engineering 477 Mechanics Division ASCE. 1979;105:127-41.

478 [29] Vecchio FJ. Finite Element Modeling of Concrete Expansion and Confinement. Journal of Structural 479 Engineering. 1992;118:2390-406. https://doi.org/10.1061/(ASCE)0733-9445(1992)118:9(2390)

480 [30] Collins DM, Klingner RE, Polyzois D. Load Deflection Behavior of Cast-in-place and retrofit 481 concrete anchors subjected to static fatigue and impact tensile loads. Austin, Texas 78712-1075: Center 482 for Transportation Research, The University of Texas at Austin; 1989. p. 241.

483 [31] Hilti. HSL-3 / HSL-GR Submission Folder. Austria: Hilti Corporation; 2013.

484 [32] Balazs GL. Cracking Analysis Based on Slip and Bond Stresses. ACI Materials Journal. $485 \quad 1993 ; 90: 340-8$.

486

487

488

[33] Lee S-C, Cho J-Y, Vecchio FJ. Model for Post-Yield Tension Stiffening and Rebar Rupture in $\begin{array}{llll}\text { Concrete } \quad \text { Members. } & \text { Engineering } & \text { Structures. } & \end{array}$ https://doi.org/10.1016/j.engstruct.2011.02.009

489 [34] fib. fib Model Code for Concrete Structures 2010. Lausanne, Switzerland: Ernst and Sohn; 2013.

490 [35] Debernardi PG, Taliano M. An Improvement to Eurocode 2 and fib Model Code 2010 Methods for 491 Calculating Crack Width in RC Structures. Structural Concrete. 2016;17:365-76. 492 https://doi.org/10.1002/suco.201500033

493 [36] He XG, Kwan AKH. Modeling Dowel Action of Reinforcement Bars for Finite Element Analysis of 494 Concrete Structures. Computers and Structures. 2001;79:595-604.

495 [37] Francesco C, Miguel FR, Aurelio M. An analysis of the shear-transfer actions in reinforced concrete 496 members without transverse reinforcement based on refined experimental measurements. Structural 497 Concrete. 2018;19:49-64. doi:10.1002/suco.201700145

498 [38] Kani MW, Huggins MW, Kani G, Wittkopp RR. Kani on Shear in Reinforced Concrete. Toronto, 499 ON, Canada: University of Toronto, Dept. of Civil Engineering; 1979.

500 [39] Collins MP, Bentz EC, Sherwood EG. Where is Shear Reinforcement Required? Review of Research 501 Results and Design Procedures. ACI Structural Journal. 2008;105:590-600.

502 [40] Muttoni A, Fernández Ruiz M. Shear Strength of Members Without Transverse Reinforcement as 503 Function of Critical Shear Crack Width. ACI Structural Journal. 2008;105:163-72.

504 [41] Cladera A, Marí A, Ribas C, Bairán J, Oller E. Predicting the shear-flexural strength of slender 505 reinforced concrete $\mathrm{T}$ and I shaped beams. Engineering Structures. 2015;101:386-98. 506 https://doi.org/10.1016/j.engstruct.2015.07.025

507 [42] Cladera A, Marí A, Bairán J-M, Oller E, Ribas C. One-Way Shear Design Method Based on a Multi508 Action Model: A compromise between simplicity and accuracy. Concrete International. 2017;39:40-6. 
509 [43] Frosch RJ, Qiang Y, Cusatis G, Bažant ZP. A Unified Approach to Shear Design. Concrete 510 International. 2017;39:47-52.

511 [44] Hong-Gun P, Kyoung-Kyu C. Unified Shear Design Method of Concrete Beams Based on 512 Compression Zone Failure Mechanism. Concrete International. 2017;39:59-63.

513 [45] Tureyen AK, Frosch RJ. Concrete Shear Strength: Another Perspective. ACI Structural Journal. $5142003 ; 100.10 .14359 / 12802$

515 [46] Kani GNJ. The Riddle of Shear Failure and its Solution. ACI Journal. 1964;61:441-68. $516 \quad 10.14359 / 7791$

517 


\section{FIGURE CAPTIONS}

519 Fig. 1: Shear strengthening systems used for specimen types a) $\mathrm{T}$ with expansion anchors and bolted 520 plates, and b) $\mathrm{P}$ with bolted plates

521 Fig. 2: Tested strengthened members (dimensions in $\mathrm{mm}$ )

522 Fig. 3: Comparison between experimental and predicted cracking pattern at failure

523 Fig. 4: Response of tested specimens with transverse reinforcement and FE predictions of the shear, crack

524 width, $w$, and crack slip, $\delta$, versus the member deflection

525 Fig. 5: Experimental and FE predictions of shear load and crack width versus member deflection for 526 specimens without transverse reinforcement

527 Fig. 6: Experimental shear versus transverse reinforcement strain and FE predictions

528 Fig. 7: Mesh of the specimen $\mathrm{T} 1$ and boundary conditions

529 Fig. 8: Modelling approach for specimen types a) S with stirrups, b) P with bolted plates and c) $\mathrm{T}$ with 530 expansion anchors and bolted plates

531 Fig. 9: Behaviour of concrete a) in tension and b) in compression, c) steel and d) expansion anchorages

532 Fig. 10: Shear resistance mechanisms vs crack width for specimens P1 and P2

533 Fig. 11: FE predictions of a) compressive and b) shear stresses at failure for type P members (MPa, mm) 
534 Fig. 12: FE parametric analysis tested members

535 Fig. 13: Ratio between the shear carried by a direct strut action $V_{\text {strut }}$ and the member capacity $V_{f e}$, both 536 determined by FE analysis, according to the shear span-to-depth ratio.

537 Fig. 14: Shear versus deflection response of member P750b with different anchor stiffness and transverse 538 reinforcement ratios of $0.13 \%, 0.17 \%$ and $0.52 \%\left(\ell_{a}\right.$ in $\left.\mathrm{mm}\right)$

539 Fig. 15: Effect of transverse stiffness on shear capacities (black and grey symbols indicate shear and 540 flexural failure respectively)

541 Fig. 16: Effect of vertical prestressing on shear capacities and shear cracking load for member P750a 
Fig. 1

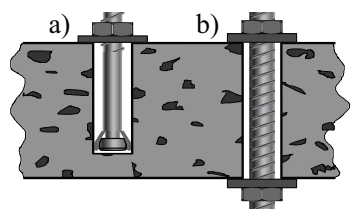


Fig. 2

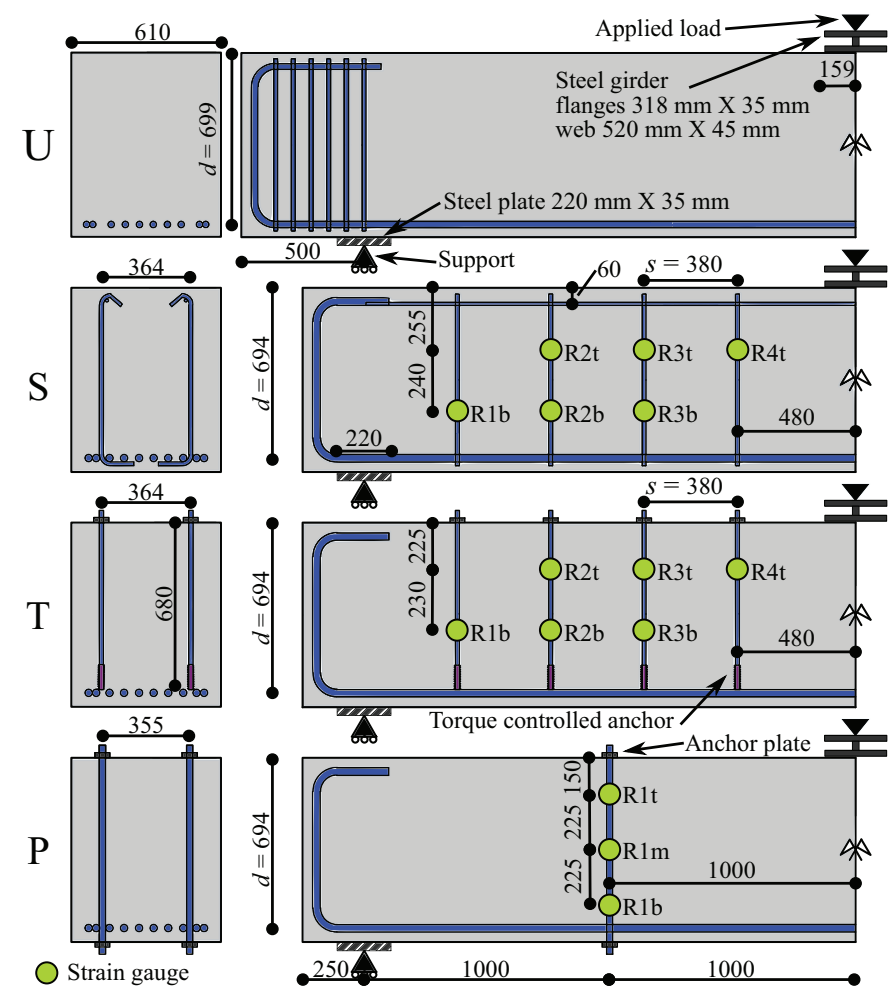


Fig. 3

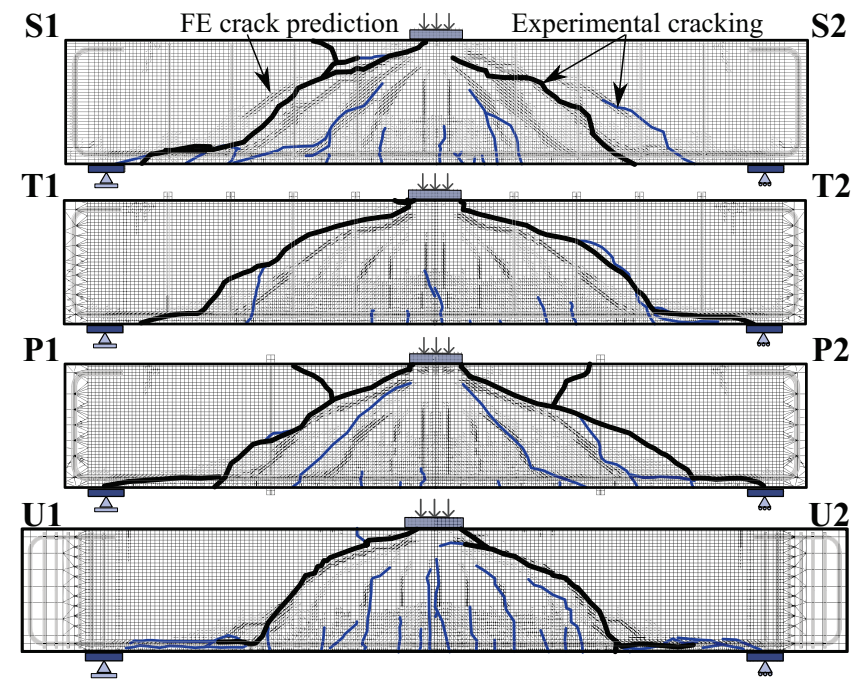


Fig. 4

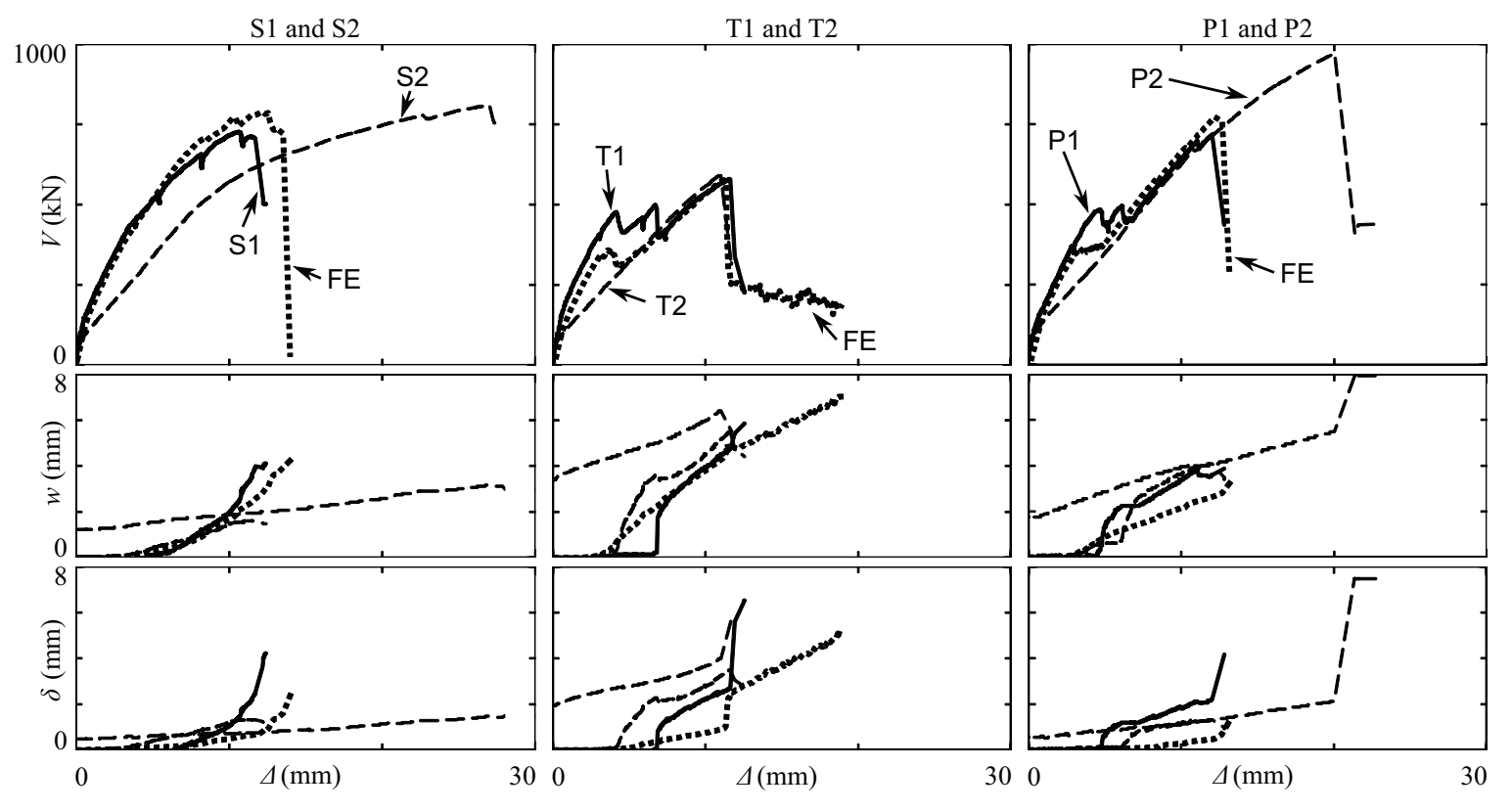


Fig. 5

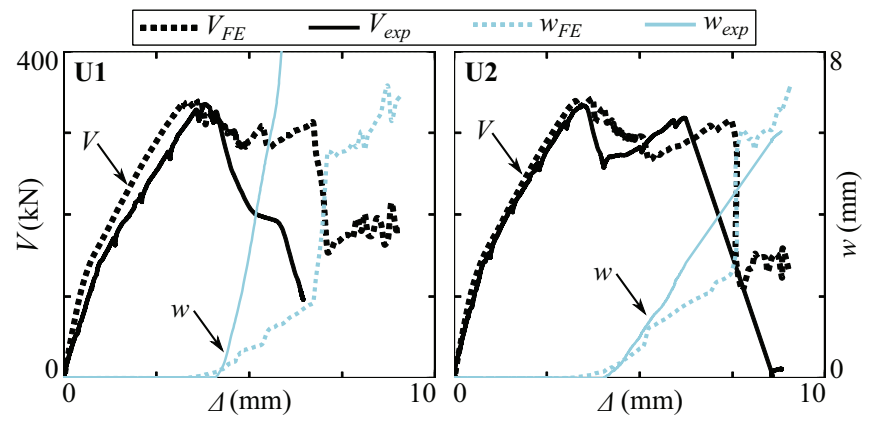


Fig. 6
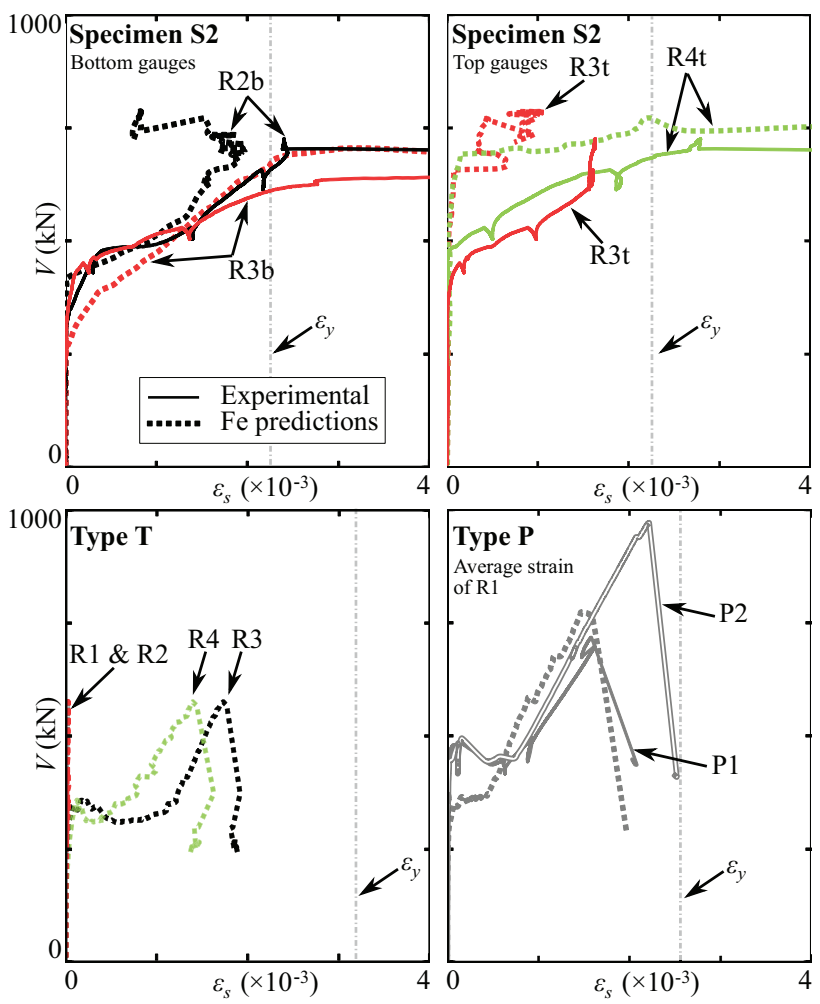
Fig. 7

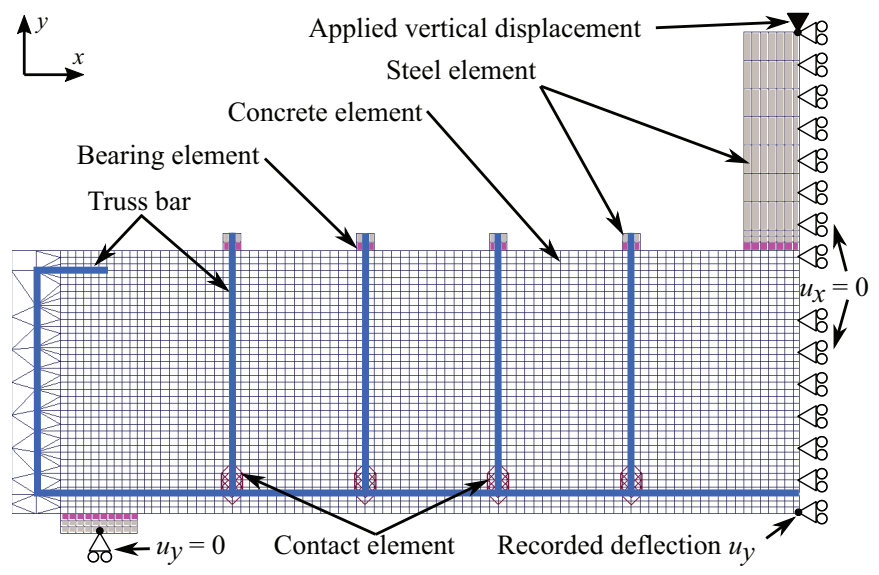


Fig. 8

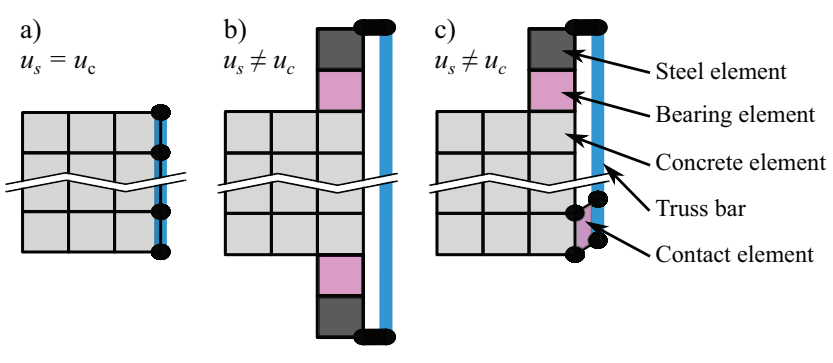


Fig. 9
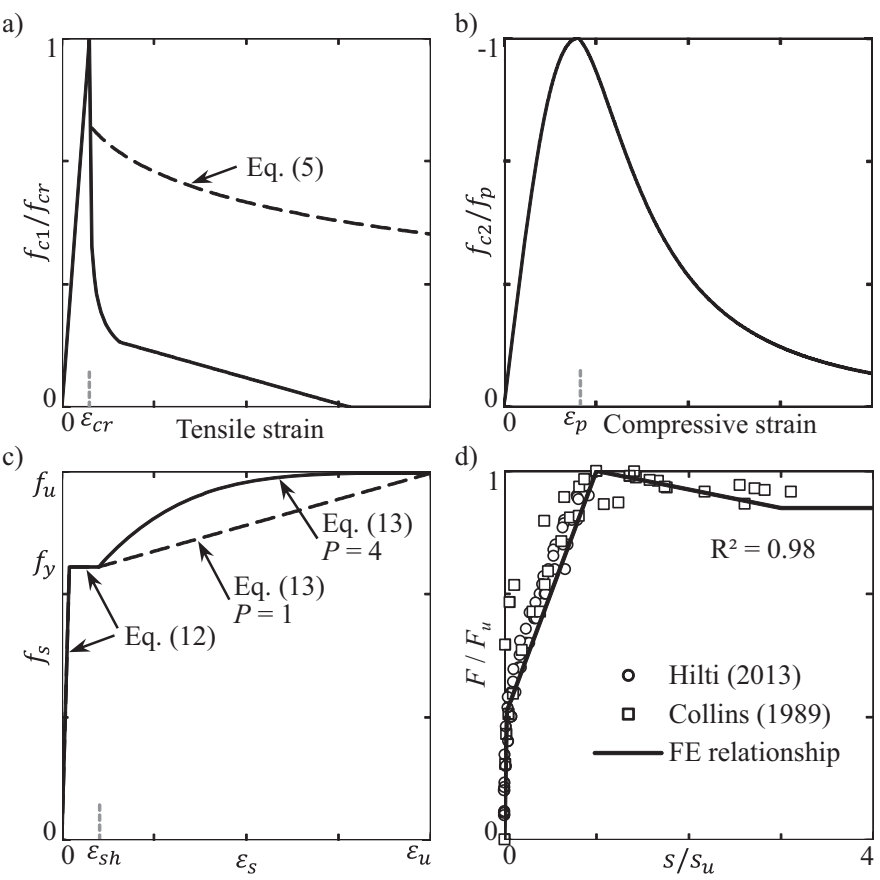
Fig. 10

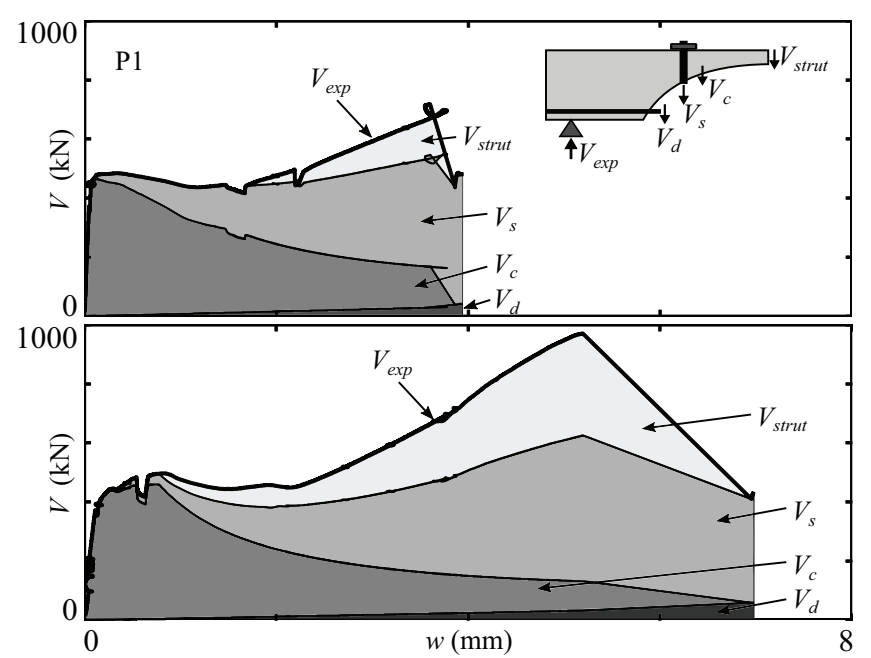


Fig. 11

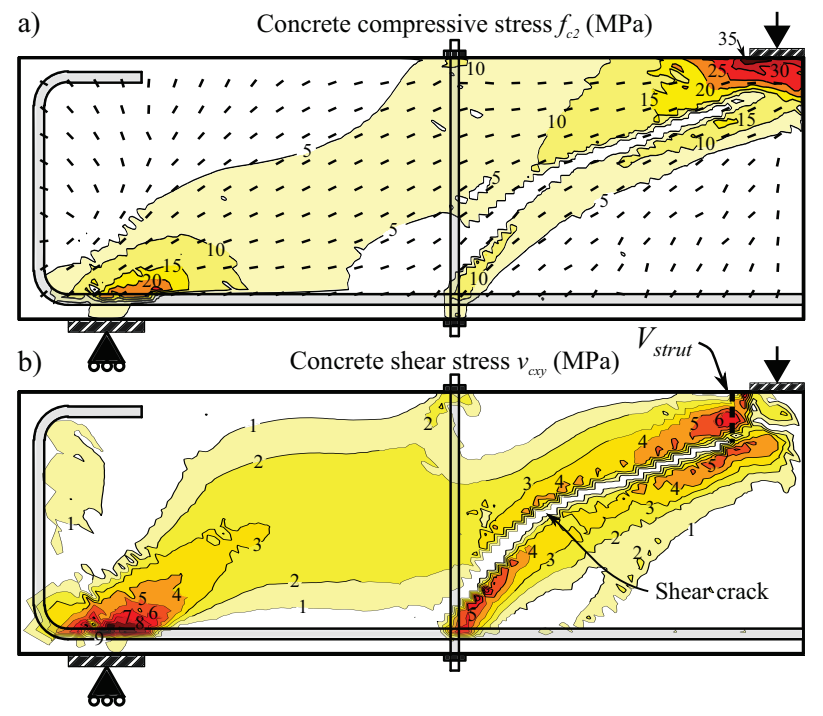


Fig. 12

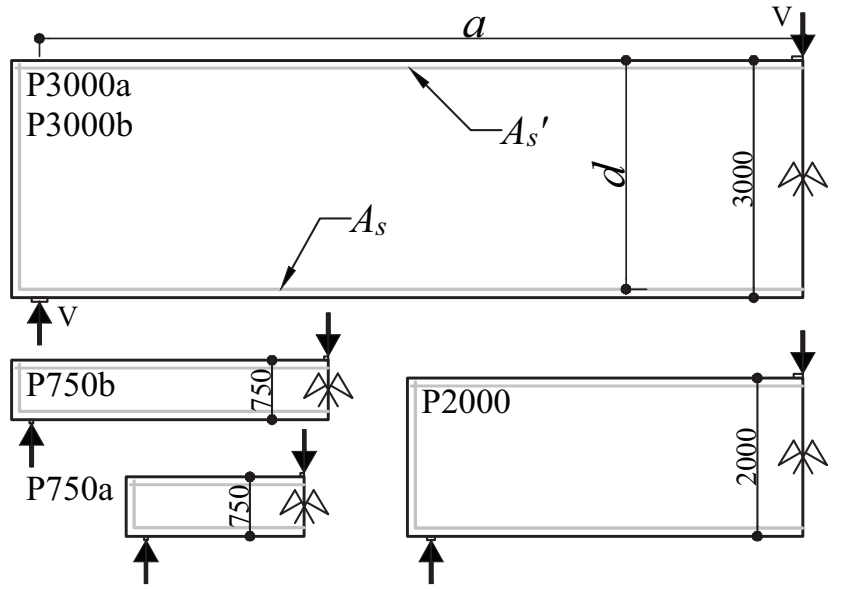


Fig. 13

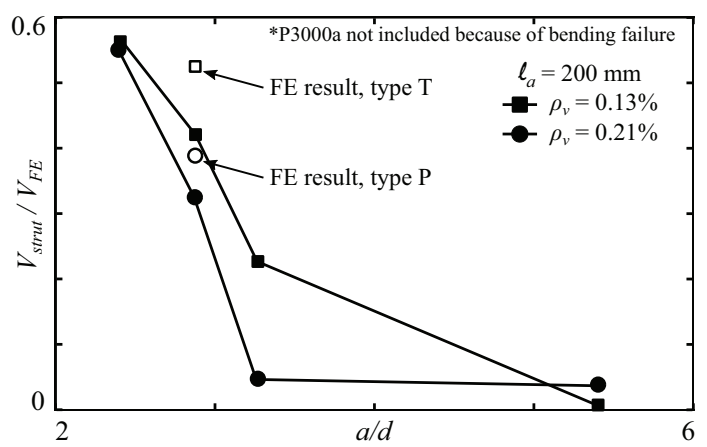


Fig. 14
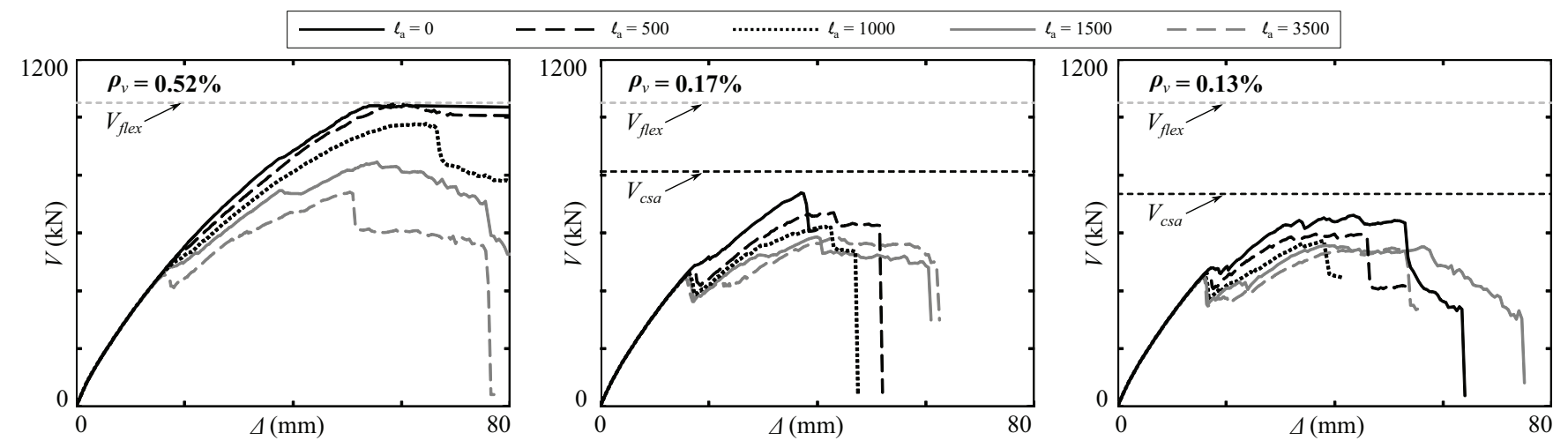
Fig. 15

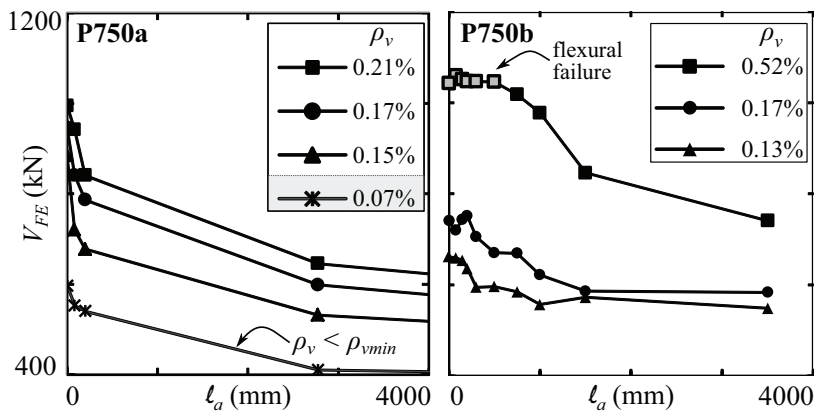


Fig. 16

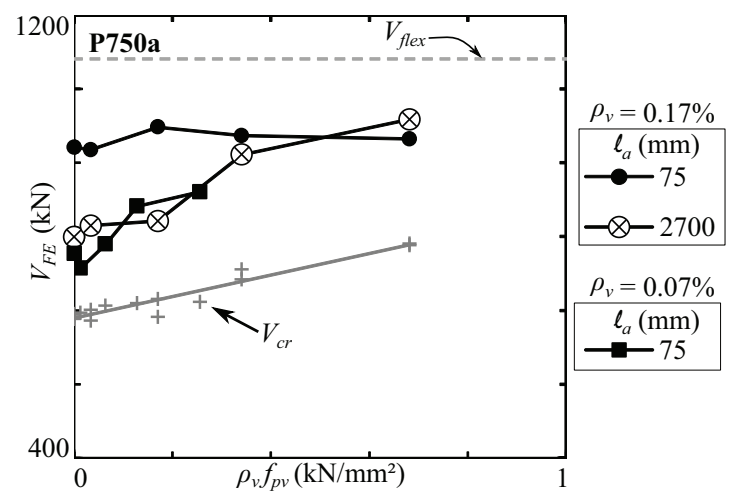


Table 1: Concrete and shear reinforcement properties

\begin{tabular}{llllllll}
\hline Type & $\begin{array}{l}\text { Strengthening } \\
\text { system }\end{array}$ & $f_{c}^{\prime}$ & $E_{c}$ & $A_{v}$ & $s$ & $f_{y}$ & $f_{u}$ \\
& $\mathrm{MPa}$ & $\mathrm{MPa}$ & $\mathrm{mm}^{2}$ & $\mathrm{~mm}$ & $\mathrm{MPa}$ & $\mathrm{MPa}$ \\
\hline $\mathrm{U}$ & None & 34.5 & 29406 & - & - & - & - \\
$\mathrm{S}$ & Stirrups & 33.3 & 25705 & 400 & 380 & 447 & 633 \\
$\mathrm{~T}$ & Expansion & 31.5 & 24144 & 292 & 380 & 642 & 800 \\
$\mathrm{P}$ & Plate & 31.2 & 25333 & 1290 & 1000 & 517 & 690 \\
\hline
\end{tabular}


Table 2: Experimental results at shear cracking and at shear failure, and comparison to predictions

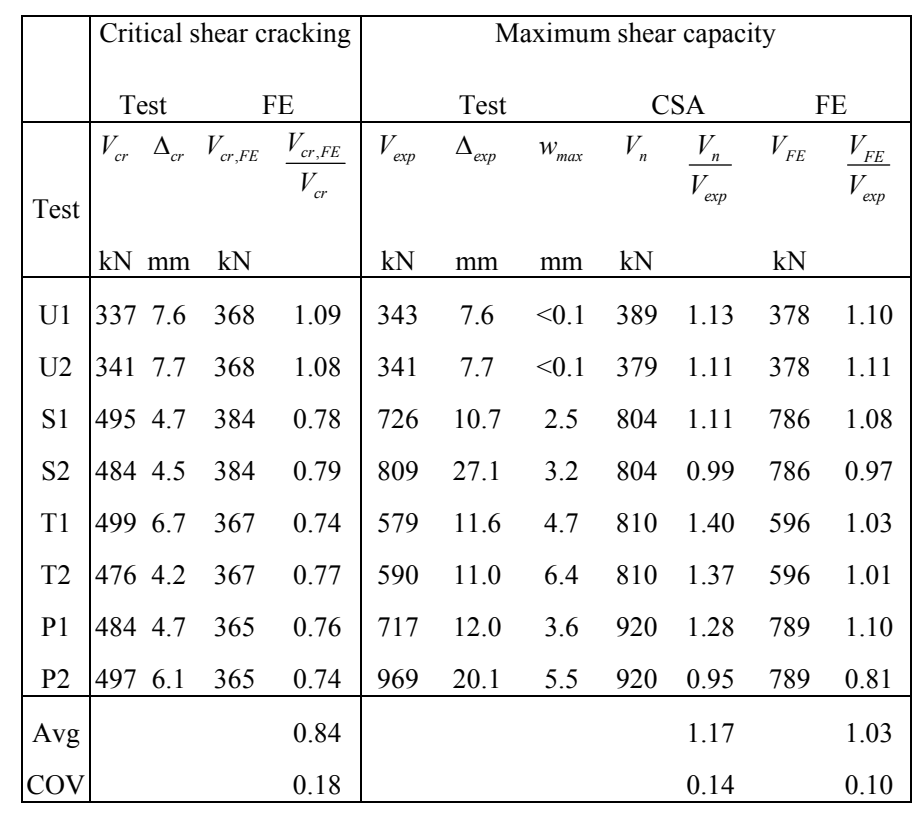


Table 3: Members properties for the parametric analysis

\begin{tabular}{llllllllll}
\hline Beam & $h$ & $d$ & $a / d$ & $\rho$ & $A_{s}^{\prime}$ & $\rho_{v \max }$ & $V_{\text {flex }}$ & $V_{c}$ & $n$ \\
& $\mathrm{~mm}$ & $\mathrm{~mm}$ & $\mathrm{~mm}$ & $\%$ & $\mathrm{~mm}^{2}$ & $\%$ & $\mathrm{kN}$ & $\mathrm{kN}$ & \\
\hline P750a & 750 & 694 & 2.9 & 1.65 & 400 & 0.33 & 1081 & 387 & 52 \\
P750b & 750 & 694 & 5.4 & 3.31 & 400 & 0.52 & 913 & 436 & 42 \\
P2000 & 2000 & 1944 & 2.4 & 0.59 & 800 & 0.13 & 1397 & 524 & 6 \\
P3000a & 3000 & 2944 & 3.3 & 0.39 & 7000 & 0.26 & 1051 & 774 & 6 \\
P3000b & 3000 & 2944 & 3.3 & 1.02 & 7000 & 0.26 & 2686 & 1028 & 21 \\
\hline Total & & & & & & & & & 127 \\
\hline
\end{tabular}

For all beams, $b_{w}=610 \mathrm{~mm}, a_{g}=20 \mathrm{~mm}, f_{c}^{\prime}=34.5 \mathrm{MPa}$

For longitudinal reinforcement, $E_{s}=200000 \mathrm{MPa}, f_{y}=508 \mathrm{MPa}$

For shear reinforcement, $\rho_{v}$ between 0 and $\rho_{v, \max }, f_{y}=448 \mathrm{MPa}$ 